\title{
Catalytic Mechanism of Guanine Deaminase: An ONIOM and Molecular Dynamics Study
}

\author{
Lishan Yao, ${ }^{\dagger, \S}$ Robert I. Cukier, ${ }^{*}, \dagger, \S$ and Honggao Yan $*, \hbar, \S$ \\ Department of Chemistry, Department of Biochemistry and Molecular Biology, and MSU Center for Biological \\ Modeling, Michigan State University, East Lansing, Michigan 48824
}

Received: November 6, 2006; In Final Form: January 24, 2007

\begin{abstract}
The catalytic mechanism of Bacillus subtilis guanine deaminase (bGD), a $\mathrm{Zn}$ metalloenzyme, has been investigated by a combination of quantum mechanical calculations using the multilayered ONIOM method and molecular dynamics simulations. In contrast to a previously proposed catalytic mechanism, which requires the bound guanine to assume a rare tautomeric state, the ONIOM calculations showed that the active-site residues of the enzyme do not affect the tautomeric state of guanine, and consequently the bound guanine is a tautomer that is the most abundant in aqueous solution. Two residues, Glutamate 55 and Aspartate 114, were found to play important roles in proton shuttling in the reaction. The proposed reaction path is initiated by proton transfer from a Zn-bound water to protonate Asp114. This process may be quite complex and rather dynamic in nature, as revealed by the molecular dynamics (MD) simulations, whereby another water may bridge the $\mathrm{Zn}$-bound water and Asp114, which then is eliminated by positioning of guanine in the active site. The binding of guanine stabilizes protonated Asp114 by hydrogen bond formation. Asp114 can then transfer its proton to the $\mathrm{N} 3$ of the bound guanine, facilitating the nucleophilic attack on $\mathrm{C} 2$ of the guanine by the Zn-bound hydroxide to form a tetrahedral intermediate. This occurs with a rather low barrier. Glu55 then transfers a proton from the $\mathrm{Zn}$-hydroxide to the amino group of the reaction intermediate and, at this point, the $\mathrm{C} 2-\mathrm{N} 2$ bond has lengthened by $0.2 \AA$ compared to guanine, making $\mathrm{C} 2-\mathrm{N} 2$ bond cleavage more facile. The $\mathrm{C} 2-\mathrm{N} 2$ bond breaks forming ammonia, with an energy barrier of $\sim 8.8 \mathrm{kcal} / \mathrm{mol}$. Ammonia leaves the active site, and xanthine is freed by the cleavage of the $\mathrm{Zn}-\mathrm{O} 2$ bond, with a barrier $\sim 8.4 \mathrm{kcal} / \mathrm{mol}$. Along this reaction path, the highest barrier comes from $\mathrm{C} 2-\mathrm{N} 2$ bond cleavage, while the barrier from the cleavage of the $\mathrm{Zn}-\mathrm{O} 2$ bond is slightly smaller. The $\mathrm{Zn}-\mathrm{O} 2$ bond can be broken without the assistance of water during the release of xanthine.
\end{abstract}

\section{Introduction}

Guanine deaminase (GD), a Zn metalloenzyme, catalyzes the hydrolytic deamination of guanine to xanthine (Scheme 1) and plays a critical role in guanine catabolism. ${ }^{1}$ Because the purine salvage pathway is asymmetric, that is, only adenine derivatives can be converted to guanine nucleotide, not vice versa, the enzyme is believed to play an important role in regulating the guanine nucleotide pool., ${ }^{1,2}$ Two families of GDs have evolved in nature, one with $\sim 160$ amino residues such as Bacillus subtilis GD $(\mathrm{bGD})^{1}$ and the other with $>400$ residues such as Escherichia coli ${ }^{3}$ and mammalian GDs. ${ }^{4-6}$ In mammals, the GD gene expression is tissue-specific and development-dependent. ${ }^{4,5,7,8}$ Because of its near absence in normal human serum, erythrocytes, and lymphoid cells, the GD activity is a specific and sensitive index for the diagnosis of liver diseases..$^{9,10}$

The crystal structure of bGD has been determined at $1.17 \AA$ resolution. ${ }^{11}$ The enzyme belongs to the cytidine deaminase superfamily, but, surprisingly, the two subunits form an intertwined dimeric protein by domain swapping (Figure 1A). The high thermal stability of bGD is attributed to the domain swapping. ${ }^{11}$ The homodimer contains two active sites, with a Zn atom coordinated with His53, Cys83, and Cys86 and a water

* To whom correspondence should be addressed. H.Y.: Phone: $517-$ 353-5282; fax: 517-353-9334; e-mail: yanh@msu.edu. R.I.C.: Phone: 517355-9715 ×263; fax: 517-353-1793; e-mail: cukier@cem.msu.edu.

$\dagger$ Department of Chemistry.

$\doteqdot$ Department of Biochemistry and Molecular Biology.

$\S$ MSU Center for Biological Modeling.
SCHEME 1: The Deamination Reaction Catalyzed by Guanine Deaminase
Guanine

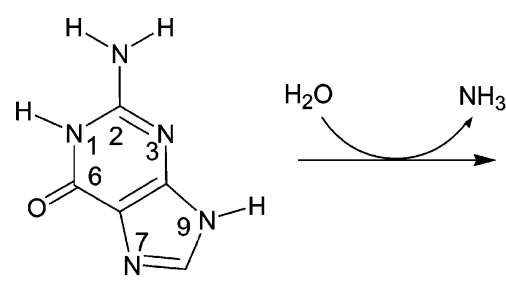

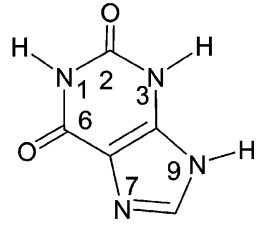

Xanthine molecule in each of the active sites (Figure 1B). The $\mathrm{Zn}$ coordination chemistry is very similar to that of yeast cytosine deaminase (yCD). ${ }^{12,13}$ The active sites are in a closed conformation, each bound with an imidazole and three water molecules (Figure 1B). A transition-state analogue has been docked into the active site on the basis of the imidazole and water molecules. ${ }^{11}$ A catalytic mechanism with Glu55 serving as a proton shuttle has been proposed ${ }^{11}$ but, in this mechanism, the guanine must be in a tautomeric form that is a rare species undetectable when it is in aqueous solution. ${ }^{14,15}$

In this work, we performed a series of quantum chemical calculations and molecular dynamics simulations to study the bGD reaction mechanism. A two-layered ONIOM ${ }^{16-19}$ method implemented in Gaussian $03^{20}$ was used for the quantum calculations. The ONIOM method is a hybrid computational method allowing different levels of theory to be applied to 

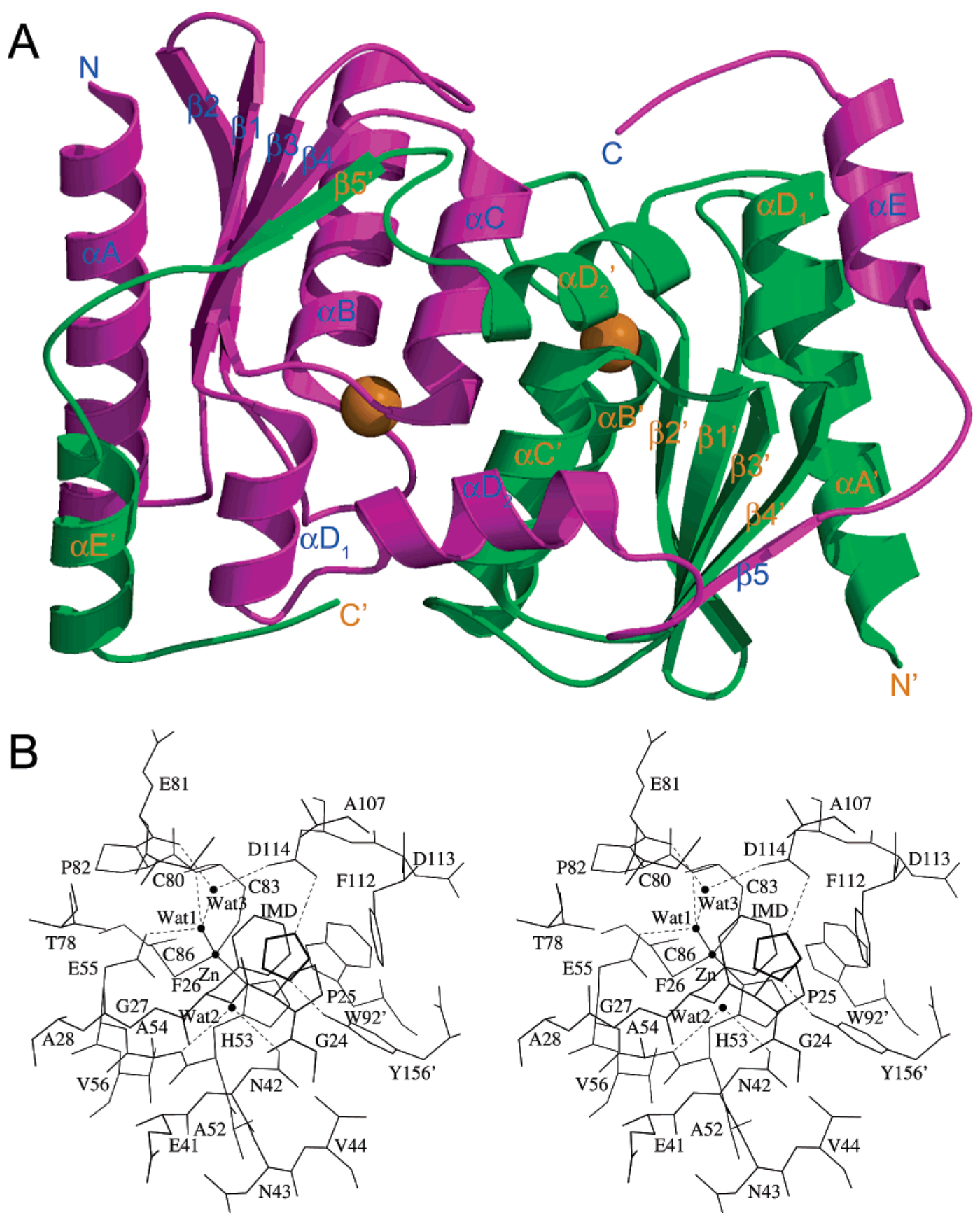

Figure 1. (A) Ribbon representation of bGD according to the coordinates of the $1.17 \AA$ crystal structure. ${ }^{11}$ One subunit is drawn in magenta, and the other in green. Both $\mathrm{Zn}$ atoms are drawn in orange spheres. The $\alpha$-helices and $\beta$-strands are labeled according to Liaw et al. (B) The active site of bGD with the bound imidazole. ${ }^{11}$ The amino acid residues are drawn in thin lines and the bound imidazole in thick lines. The Zn atom and the three bound water molecules (Wat1, Wat2, and Wat3) are drawn in black spheres. The hydrogen bonds involving the imidazole and water molecules are indicated by dashed lines. The figure was prepared with Molscript ${ }^{53}$ and Raster3D. ${ }^{54,55}$

different parts of a molecular system. A variety of enzymatic reactions have been studied by the ONIOM method in recent years. ${ }^{21-26}$ Molecular dynamics (MD) simulations, which can efficiently provide important configurational properties of the protein and account for solvation effects, are used to complement the ONIOM calculations. ${ }^{27}$

Quantum chemical energetic based methods can only lead to the suggestion of possible mechanisms. In addition to the compromises of level of calculation that must be made for these large systems, results of greater accuracy would also require the incorporation of methods to obtain the free energy along the reaction pathway. Several quantum mechanics/molecular mechanics (QM/MM) protocols have been developed to incorporate configurational sampling while accounting for chemical transformations, which involve a tradeoff between the quality (cost) of the quantum chemical part and the extent of configurational sampling. ${ }^{28-33}$ Some aspects of the catalytic mechanisms of the related enzymes cytosine deaminase ${ }^{34}$ and cytidine deaminase ${ }^{35,36}$ were recently studied by QM/MM methods.

Our ONIOM calculations suggest that the active site residues of the enzyme do not affect the tautomeric state of guanine and, consequently, the bound guanine is the tautomer that is the most abundant in aqueous solution. The combination of the ONIOM calculations and the MD simulations allows us to propose a complete reaction path for the bGD-catalyzed reaction. Two residues, Glutamate 55 and Aspartate 114, are found to play key roles in proton shuttling in the reaction. 


\section{Methods}

ONIOM Calculation. The initial models for the computational studies were based on the $1.17 \AA$ crystal structure of the imidazole-bound bGD. ${ }^{11}$ Guanine was docked to an active site of bGD by superimposing the imidazole moiety of guanine with the bound imidazole and $\mathrm{O} 6$ of guanine with a tightly bound water molecule in a manner similar to that for docking a transition-state analogue to the active site of bGD. ${ }^{11}$ The missing hydrogen atoms were built using Insight II (Accelrys, San Diego).

The enzyme was modeled with 26 residues within $6 \AA$ of the bound guanine, including Gly24, Pro25, Phe26, Gly27, Ala28, Glu41, Asn42, Asn43, Val44, Ala52, His53, Ala54, Glu55, Val56, Thr78, Cys80, Glu81, Pro82, Cys83, Cys86, Ala107, Phe112, Asp113, Asp114, Trp92', and Tyr156' (Figure $1 \mathrm{~B})$, where the prime signs indicate residues from the adjacent subunit. An MD simulation shows that these residues contribute most of the interaction energies between ligand and surroundings (see the Results section). The system was divided into two layers. The inner layer, which was treated with a high level of theory (the B3LYP functional ${ }^{37,38}$ with the $6-31 \mathrm{G}^{*}$ basis set), consisted of the substrate, the intermediate, or the products, the $\mathrm{Zn}$, the imidazole ring (model for His53), $\mathrm{CH}_{3} \mathrm{CH}_{2} \mathrm{COO}^{-}$(model for Glu55), $\mathrm{SCH}_{3}$ (model for Cys83 and Cys86), $\mathrm{CH}_{3} \mathrm{COO}^{-}$ (model for Asp114), and the water coordinated to the $\mathrm{Zn}$. The rest of system was treated with a lower level of theory $\left(\mathrm{AM} 1^{39}\right)$. Quantum chemical studies on model compounds show that the $\mathrm{Zn}$-ligand distances are sensitive to their protonation states. ${ }^{40,41}$ The $\mathrm{Zn}$ coordination in bGD is essentially identical to that in yCD with very similar distances according to their crystal structures. ${ }^{13}$ The four distances in bGD (yCD) are $\mathrm{Zn}-\mathrm{O} 2.03$

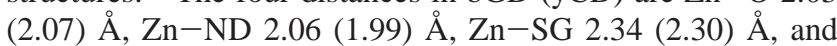
$\mathrm{Zn}-\mathrm{SG} 2.28$ (2.28) $\AA$. Therefore, the protonation states of the $\mathrm{Zn}$ ligands were set the same as in the yCD complex with SG (the sulfur atom) of Cys83, Cys8, and ND (the delta nitrogen) of His53 deprotonated. ${ }^{21,27}$

In Morokuma and co-workers' terminology, the entire system is called "real" and is treated with the low level of theory. The inner layer is termed "model" and is treated with both the low and high levels of theory. The total ONIOM energy $E^{\mathrm{ONIOM}}$ is given by ${ }^{16,42} E^{\mathrm{ONIOM}}=E($ high, model $)+E($ low, real $)-E($ low, model). In the ONIOM procedure, the geometry of the inner layer is optimized for all the species while the atoms of the outer layer are fixed at their crystallographic positions, because optimization of the outer layer might lead to an unrealistic expansion of the protein. ${ }^{24}$ The MD simulation shows that the protein is quite rigid, especially, the active site in both the reactant guanine and the product xanthine bound forms, which suggests that freezing the outer layer is a reasonable approximation (see the Results section). Energy barriers were estimated by scanning the desired reaction coordinates. Therefore, the barriers are upper bounds to the true reaction barriers.

MD Simulations of the Apo bGD and the Guanine-Bound Complex. In the MD simulations, the RESP charges of $\mathrm{Zn}, \mathrm{Zn}$ bound water, and the side chains of His53, Cys83, and Cys86 as well as the bond, angle, and dihedral force constants of the $\mathrm{Zn}$ complex were taken from the $\mathrm{yCD}$ apo form simulation, considering the similarity of the $\mathrm{Zn}$ coordinations in the two crystal structures. ${ }^{11,13}$ Atom-centered partial charges of guanine were derived by using the AMBER antechamber program (RESP methodology) ${ }^{43}$ on the basis of an HF/6-31G* quantum calculation.

Starting coordinates for the protein atoms were taken from the crystal structure. ${ }^{11}$ Imidazole was removed from the active site of subunit one, while it was mutated to guanine in the active site of subunit two. Thus, subunit one is the apo form while subunit two is the guanine-bound complex. All the crystal water molecules were maintained. The protonation states of the ionizable residues were set to their normal values at $\mathrm{pH}$ 7. The protein was solvated by a layer of $\sim 18000$ TIP3P ${ }^{44}$ water molecules, which extended $12.5 \AA$ from the outermost protein atoms and resulted in a periodic box of the dimensions $72 \times$ $96 \times 85 \AA^{3}$. Twelve $\mathrm{Na}^{+}$ions were placed by the Leap program ${ }^{43}$ to neutralize the -12 charge of the model system. The parm94 version of the all-atom AMBER force field ${ }^{45}$ was used for all the simulations.

MD simulations were carried out using the SANDER module in AMBER 7.0. ${ }^{43}$ The SHAKE algorithm was used to constrain the bond lengths of all bonds involving hydrogen atoms permitting a 2-fs time step. ${ }^{46}$ A nonbonded pair list cutoff of 8.0 $\AA$ was used and the nonbonded pair list was updated every 25 steps. The Particle-Mesh-Ewald method was used to include the contributions of long-range electrostatic interactions. ${ }^{47}$ The volume and the temperature $(300 \mathrm{~K})$ of the system were controlled during the MD simulations by Berendsen et al.'s method. ${ }^{48}$

The simulation time was 2 ns with a 500-ps equilibration period. Coordinates were saved every 2 ps. All of the MD results were analyzed by using the PTRAJ module of AMBER 7.0. In these analyses, hydrogen bonds were assigned when the distance between two heavy atoms $(\mathrm{O}$ or $\mathrm{N})$ is less than $3.5 \AA$ and the angle (heavy atom-hydrogen-heavy atom) is greater than $120^{\circ}$.

MD Simulation of the Xanthine-Bound bGD. To understand whether water assists the $\mathrm{Zn}-\mathrm{O} 2$ bond cleavage during xanthine release, an MD simulation of the xanthine-bound form was performed. One xanthine was docked to each active site in the bGD crystal structure, and the active sites were then minimized with ONIOM. In subunit one, the distance between $\mathrm{Zn}$ and $\mathrm{O} 2$ is harmonically restrained around $3.10 \AA$ using a force constant of $100 \mathrm{kcal} /\left(\mathrm{mol}-\AA^{2}\right)$, which mimics the transition state for $\mathrm{Zn}-\mathrm{O} 2$ bond cleavage. In subunit two, the distance was restrained around $3.80 \AA$ with the same force constant mimicking the xanthine-bound form with the $\mathrm{Zn}-\mathrm{O} 2$ bond broken. Both distances are obtained from the corresponding ONIOM calculations.

The force constants for the $\mathrm{Zn}$ complex were the same as those used for MD simulations of the apo and guanine-bound bGD. The RESP charges for xanthine were obtained by using the RESP program as for guanine but on the basis of B3LYP $6-31+\mathrm{G}^{*}$ calculations of ONIOM optimized active-site structures that were trimmed to only include His53, Glu55, Cys83, Cys86, Asp114, Zn, and xanthine. ${ }^{27}$ Only the charges of the side chains of His53, Cys83, and Cys86, as well as the charges of $\mathrm{Zn}$ and xanthine, were modified. Product ammonia was substituted by one water molecule in each active site, considering that the release of ammonia should be easier than xanthine. A 2-ns MD trajectory was obtained by using the same protocol as described above for the simulations of the apo and the guanine-bound bGD, and the data were analyzed by using the PTRAJ program.

\section{Results}

Reproduction of the $\mathbf{Z n}$ Coordination Chemistry with ONIOM. In the ONIOM calculations, the B3LYP functional ${ }^{37,38}$ with the $6-31 \mathrm{G}^{*}$ basis set was used for the treatment of the inner layer of the system, while AM1 was used for the rest of the system. ${ }^{39}$ To validate the ONIOM method used in this work, the $\mathrm{Zn}$ coordination in the imidazole-bound bGD ${ }^{11}$ was repro- 
TABLE 1: Comparison of the ONIOM Optimized Structure with the Crystal Structure of the Imidazole-Bound Complex

\begin{tabular}{lrc}
\hline \multicolumn{1}{c}{ internal coordinate } & ONIOM $^{a}$ & X-ray Structure $^{a}$ \\
\hline Zn-O (wat) & 1.96 & 2.03 \\
Zn-ND (His53) & 2.03 & 2.06 \\
Zn-SG (Cys83) & 2.41 & 2.34 \\
Zn-SG (Cys86) & 2.37 & 2.28 \\
SG(Cys83)-Zn-SG(Cys86) & $115.6^{\circ}$ & $130.7^{\circ}$ \\
SG(Cys83)-Zn-ND(His53) & $101.9^{\circ}$ & $105.0^{\circ}$ \\
SG(Cys86)-Zn-ND(His53) & $105.9^{\circ}$ & $112.7^{\circ}$ \\
SG(Cys83)-Zn-O(wat) & $110.5^{\circ}$ & $106.8^{\circ}$ \\
${ }^{a}$ Distances in $\AA$. & &
\end{tabular}

duced by the method. (Imidazole was treated at the high level, which confirms the assignment of the protonation state of the imidazole ring.) The calculated distances and angles for the $\mathrm{Zn}$ complex are summarized in Table 1. The excellent agreement between the calculated distances and angles with those measured from the high-resolution crystal structure indicated that the ONIOM method and the level of theory are sufficient for the treatment of the metalloenzyme. We then proceeded with the exploration of various possible catalytic mechanisms with ONIOM calculations.

Substrate Binding. The substrate guanine was placed in the active site of BGD as described in the Methods section. The polar interactions between the bound substrate and the enzyme are illustrated in Figure 2. The binding between the substrate and the enzyme is stabilized by a hydrogen bond network with all hydrogen bond donors and acceptors of the substrate satisfied except N3, which is protonated as the reaction progresses. The binding is also stabilized by $\pi$-stacking interactions with the imidazole ring of His53 and the phenyl ring of Phe26, which together with the guanine form a three-layered sandwich with the guanine in the middle, similar to the binding of imidazole displayed in Figure 1B. The individual hydrogen bonds of the hydrogen bond network are listed in Table 2 along with the

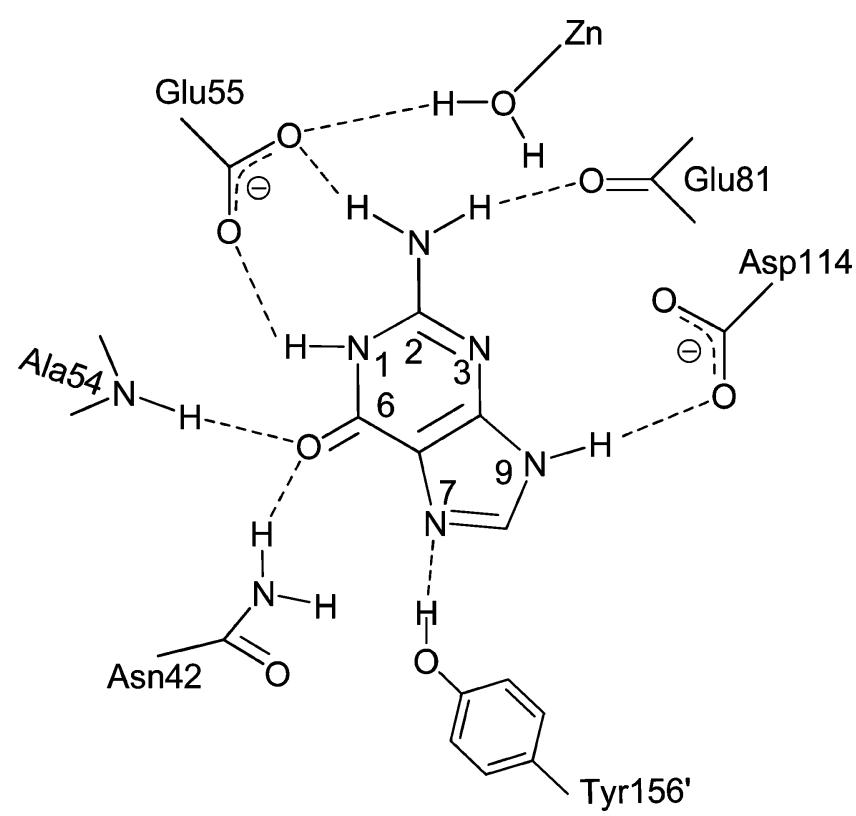

Figure 2. Hydrogen bonds between the bound-substrate guanine and the active-site residues from the ONIOM calculation.
TABLE 2: Hydrogen Bonds between the Enzyme and Guanine in the Guanine-Bound bGD ${ }^{a}$

\begin{tabular}{|c|c|c|c|}
\hline & ONIOM & $\mathrm{MD}^{b}$ & \multirow[b]{2}{*}{ occurrence $(\%)$} \\
\hline & distance $(\AA)$ & $\overline{\text { distance }(\AA)}$ & \\
\hline Asn $42-\mathrm{NDH} \cdots \mathrm{O} 6$ & 3.09 & $3.00(0.18)$ & 97.3 \\
\hline 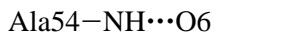 & 3.01 & $3.03(0.16)$ & 99.7 \\
\hline Glu55-OE1 $\cdots \mathrm{H}-\mathrm{N} 1$ & 2.84 & $2.88(0.16)$ & $80.1^{c}$ \\
\hline Glu55-OE2 $\cdots \mathrm{H} 1-\mathrm{N} 2$ & 3.05 & $3.11(0.22)$ & $86.5^{c}$ \\
\hline 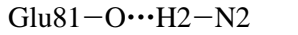 & 3.46 & $3.16(0.19)$ & 74.1 \\
\hline $\mathrm{Zn}-\mathrm{WAT}-\mathrm{OH} \cdots \mathrm{N} 3$ & 3.05 & $3.07(0.16)$ & 98.3 \\
\hline Asp114-OD1 $\cdots \mathrm{H}-\mathrm{N} 9$ & 2.73 & $2.96(0.16)$ & $98.0^{a}$ \\
\hline Tyr156'-OH $\cdots \mathrm{N} 7$ & 3.32 & $3.03(0.19)$ & 92.3 \\
\hline
\end{tabular}

${ }^{a}$ Hydrogen bonds are assigned when the distance between two heavy atoms $(\mathrm{O}$ or $\mathrm{N})$ is less than $3.5 \AA$ and the angle (heavy atomhydrogen-heavy atom) is greater than $120^{\circ} .{ }^{b}$ In the MD, OD2 also forms a hydrogen bond with $\mathrm{H}-\mathrm{N} 9$ with distance $2.96(0.18)$ and occurrence $96.8 \%{ }^{c}$ Because of the rotation of carboxyl group, $\mathrm{OE} 2(\mathrm{OE} 1)$ also forms hydrogen bond with $\mathrm{H}-\mathrm{N} 1(\mathrm{H} 1-\mathrm{N} 2)$.

distances between the heavy atoms. The amino group of guanine forms one hydrogen bond each with the carboxyl group of Glu55 and the backbone carbonyl group of Glu81. These two hydrogen bonds can assist the positioning of $\mathrm{C} 2$ for nucleophilic attack by the $\mathrm{Zn}$-bound water in the following steps. The carboxyl group of Glu55 also forms one hydrogen bond with the NH group of guanine at position 1 and another one with the $\mathrm{Zn}$ bound water molecule. In the ONIOM optimized structure, guanine forms an additional four hydrogen bonds with Asn42, Ala54, Asp114, and Tyr156' (Figure 2, Table 2). The interactions between the substrate and the enzyme are essentially the same as those between a transition-state analogue and the enzyme except those caused by the chemical differences between the substrate and the transition-state analogue. ${ }^{11}$

Tautomerization of the Bound Guanine. As will be discussed in section IV, tautomerization of the bound guanine has significant ramifications on the possible catalytic mechanism of bGD. In polar solvents, only the tautomeric form as depicted in Scheme 1 with a proton on both $\mathrm{N} 1$ and N9 was observed for neutral guanine. ${ }^{14,15}$ The free-energy difference between this tautomeric form and the tautomeric form with a proton on N3 and $\mathrm{N} 9$ was calculated to be $5.2 \mathrm{kcal} / \mathrm{mol}$ at $25{ }^{\circ} \mathrm{C} .{ }^{49}$ However, the active-site amino acid residues may affect the tautomerization of the bound guanine. Thus, it is important to address which tautomeric form the bound guanine is. Tautomerization of the bound guanine (Figure 3) was investigated with ONIOM calculations. The result indicated that tautomer $\mathbf{b}$ is $5.8 \mathrm{kcal} /$ mol less stable than tautomer $\mathbf{a}$ in the active site, similar to what was found in aqueous environment. ${ }^{49}$ Thus, the tautomeric state of the bound guanine is the same as that of free guanine in aqueous solution.

Protonation of Guanine. To activate the bound guanine and the $\mathrm{Zn}$-bound water molecule for the deamination reaction, a proton must be transferred from the water molecule to N3 of guanine. Although the $\mathrm{OH}$ of the water molecule and the N3 of guanine are within a hydrogen bond distance, the orientation of the $\mathrm{OH}$ vector is unfavorable for a hydrogen bond, which makes a direct proton transfer extremely difficult. Our ONIOM calculation indicated that the barrier for a direct transfer is $\sim 42$ $\mathrm{kcal} / \mathrm{mol}$. Thus, this transfer is unlikely to occur. Alternatively, this proton transfer may be assisted by the carboxyl group of Asp114. However, the distance between the $\mathrm{O}$ of water and the OD1 of Asp114 is quite far, $\sim 4.2 \AA$, when guanine binds, which makes the proton transfer from water to Asp114 also quite difficult. However, the energy of the protonated Asp114 and $\mathrm{Zn}$-bound hydroxide is only $0.7 \mathrm{kcal} / \mathrm{mol}$ higher than that of the deprotonated Asp144 and Zn-bound water (complex $1 \rightarrow$ 


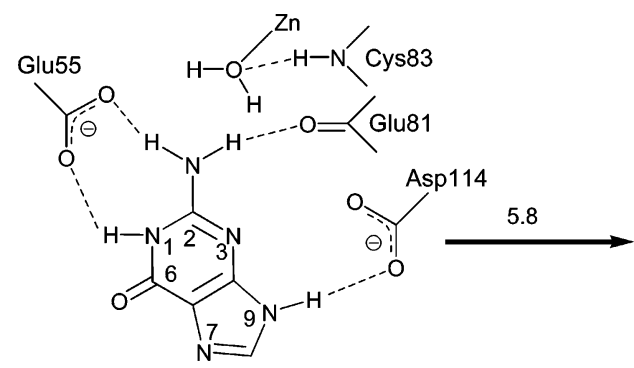

a

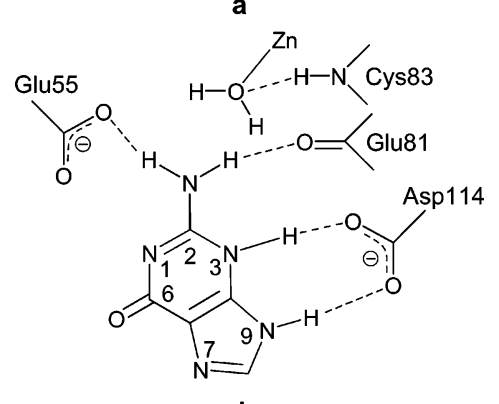

b

Figure 3. Tautomerization of guanine in the active site. Tautomer a is more stable by $5.8 \mathrm{kcal} / \mathrm{mol}$ than tautomer $\mathbf{b}$ according to the ONIOM calculation.

complex 2, Figures 4 and 5) when the substrate binds. So, from a thermodynamic point of view, the Zn-bound water can transfer its proton to OD1 of Asp114. This process will be discussed later.

After the protonation of Asp114, OD1 of Asp114 forms a new hydrogen bond with N3 of guanine (complex 2 in Figure 4) with the corresponding heavy atom distance at $2.81 \AA$, while other hydrogen bonds between the substrate and enzyme are maintained. This new hydrogen bond stabilizes protonated Asp114. The distance between $\mathrm{C} 2$ of guanine and the oxygen of the Zn-bound hydroxide is shortened to $2.46 \AA$, compared with $2.78 \AA$ before the proton transfer from the $\mathrm{Zn}$-bound water to Asp114. Apparently, this transfer favors the hydroxide nucleophilic attack.

Then, Asp114 transfers its proton to guanine (complex 3 in Figure 4) with a barrier of $4.5 \mathrm{kcal} / \mathrm{mol}$ (Figure 5) when the OD $1-\mathrm{H}$ distance is $1.25 \AA$. The barrier was calculated as follows. The distance between OD1 and the proton was first scanned by $0.1 \AA$ increments to locate approximately the maximum energy. Then, $0.05 \AA$ increments were used for the more precise determination of the maximum. Complex $\mathbf{3}$ is 0.7 $\mathrm{kcal} / \mathrm{mol}$ more stable than complex 2 (Figure 5). The proton transfer from Asp114 to guanine shortens the distance between $\mathrm{C} 2$ of guanine and the oxygen of the $\mathrm{Zn}$-bound hydroxide to $\sim 2.29 \AA$ because of the positive charge of the protonated guanine.

Formation of Tetrahedral Intermediates. After the proton transfer from the Zn-bound water to N3 via Asp114, the resultant hydroxide is well positioned for a nucleophilic attack on $\mathrm{C} 2$ of the protonated guanine. The shortened distance between $\mathrm{C} 2$ of guanine and the oxygen of the $\mathrm{Zn}$-bound hydroxide makes the nucleophilic attack facile. The barrier for this process is only $1.5 \mathrm{kcal} / \mathrm{mol}$ (Figure 5) with the distance between $\mathrm{C} 2$ of guanine and the oxygen of the hydroxide at $1.85 \AA$. The barrier was calculated by using the same method as described above. The new species (complex 4 in Figure 4 ) is $0.1 \mathrm{kcal} / \mathrm{mol}$ more stable than complex 3 (Figure 5). This process also shortens the distance between the oxygen of the $\mathrm{Zn}$-bound hydroxide and OE2 of Glu55 from $2.88 \AA$ to $2.63 \AA$, and one hydrogen bond is formed between them. The shortening of this distance facilitates the next step of the reaction, the proton transfer from the Zn-bound hydroxide to the carboxyl of Glu55.

The proton transfer from Zn-bound hydroxyl to Glu55 is composed of two substeps: (1) rotation of the amino group of the tetrahedral intermediate to orient $\mathrm{N} 2-\mathrm{H} 1$ to other directions so that OE2 of Glu55 can extract the proton from the hydroxyl and (2) proton transfer to OE2 of Glu55. The energy of the new complex (complex $\mathbf{5}$ in Figure 4) is $3.3 \mathrm{kcal} / \mathrm{mol}$ higher than that of complex 4 (Figure 5). Since the reaction coordinates for this process are rather complicated, the barrier was estimated on the basis of the stepwise process, $\sim 4.2 \mathrm{kcal} / \mathrm{mol}$ from substep 2 with the OE2-H distance at $1.20 \AA$. Considering that the energy difference between complexes $\mathbf{5}$ and $\mathbf{4}$ is $3.3 \mathrm{kcal} / \mathrm{mol}$ (Figure 5), the real barrier should be between 3.3 and $4.2 \mathrm{kcal} /$ mol.

After the proton transfer from the Zn-bound hydroxyl to Glu55, the carboxyl group of Glu55 rotates $\sim 30^{\circ}$ to orient $\mathrm{OE} 2 \mathrm{H}$ to the amino group of the reaction intermediate and then transfers this proton to the amino group. The barrier for this step is $2.6 \mathrm{kcal} / \mathrm{mol}$, with the distance between $\mathrm{N} 2$ and the proton at $2.05 \AA$. This new complex (complex 6 in Figure 4) is 4.1 $\mathrm{kcal} / \mathrm{mol}$ more stable than complex 5 (Figure 5).

The bond length between N2 and C2 was monitored for these reaction steps. Interestingly, this bond is lengthened significantly after the nucleophilic attack as well as the protonation of the amino group. The bond length is $1.37 \AA$ in complex $\mathbf{1}, 1.36 \AA$ in complex 2, $1.35 \AA$ in complex $\mathbf{3}, 1.44 \AA$ in complex $4,1.46$ $\AA$ in complex 5, and $1.56 \AA$ in complex 6. The first significant increase (from complex 3 to complex 4 ) may be caused by the hybridization change of $\mathrm{C} 2$ from $\mathrm{sp}^{2}$ to $\mathrm{sp}^{3}$, which weakens the correlation between the N $2 \pi$ electrons and the purine ring $\pi$ electrons, while the second significant increase (from complex 5 to complex 6 ) may be caused by the $\mathrm{N} 2$ orbital hybridization change from $\mathrm{sp}^{2}$ to $\mathrm{sp}^{3}$. This $0.2 \AA$ lengthening of the $\mathrm{C} 2-\mathrm{N} 2$ bond should make the $\mathrm{C} 2-\mathrm{N} 2$ bond cleavage much easier in the next step.

Formation of Products. When the amino group is protonated (complex 6), the $\mathrm{C} 2-\mathrm{N} 2$ bond can be cleaved to form the $\mathrm{Zn}$ bound xanthine and ammonia. The distance between $\mathrm{C} 2$ and $\mathrm{N} 2$ was scanned, and the maximum energy was found at the distance $2.10 \AA$ with a barrier of $8.8 \mathrm{kcal} / \mathrm{mol}$ (Figure 5). The product complex (complex 7 in Figure 4) is $5.9 \mathrm{kcal} / \mathrm{mol}$ less stable than complex 6 (Figure 5). The stationary position was found for ammonia at the distance $2.79 \AA$ where it forms two hydrogen bonds with OE2 of Glu55 and the carbonyl of Glu81. The hydrogen bond distances are $2.97 \AA$ (between $\mathrm{N}$ of ammonia and OE2 of Glu55) and $3.17 \AA$ (between $\mathrm{N}$ of ammonia and carbonyl $\mathrm{O}$ of Glu81), indicating that ammonia is loosely bound in the active site, which should favor complex 7 more than complex 6 from an entropic point of view. Once ammonia is released, this reaction will not be reversible.

Therefore, from complex 1 to complex 7, the overall reaction is endothermic with $\sim 5.0 \mathrm{kcal} / \mathrm{mol}$ energy difference (Figure 5 ), and the rate-limiting step is the $\mathrm{C} 2-\mathrm{N} 2$ bond cleavage with a barrier of $8.8 \mathrm{kcal} / \mathrm{mol}$ (complex 6 to complex 7).

Release of Xanthine. After the release of ammonia, $\mathrm{O} 2$ of xanthine is still coordinated with the $\mathrm{Zn}$, and this coordination bond has to be broken to release xanthine (complex $\mathbf{8}$ in Figure 6). The $\mathrm{Zn}-\mathrm{O}$ bond was scanned and the maximum energy was found at the distance $3.10 \AA$ with a barrier of $8.4 \mathrm{kcal} / \mathrm{mol}$, which is slightly smaller than the barrier for the $\mathrm{C} 2-\mathrm{N} 2$ bond cleavage in the previous step. The complex becomes stabilized (complex 9 in Figure 6) when this distance increases to $3.79 \AA$ 

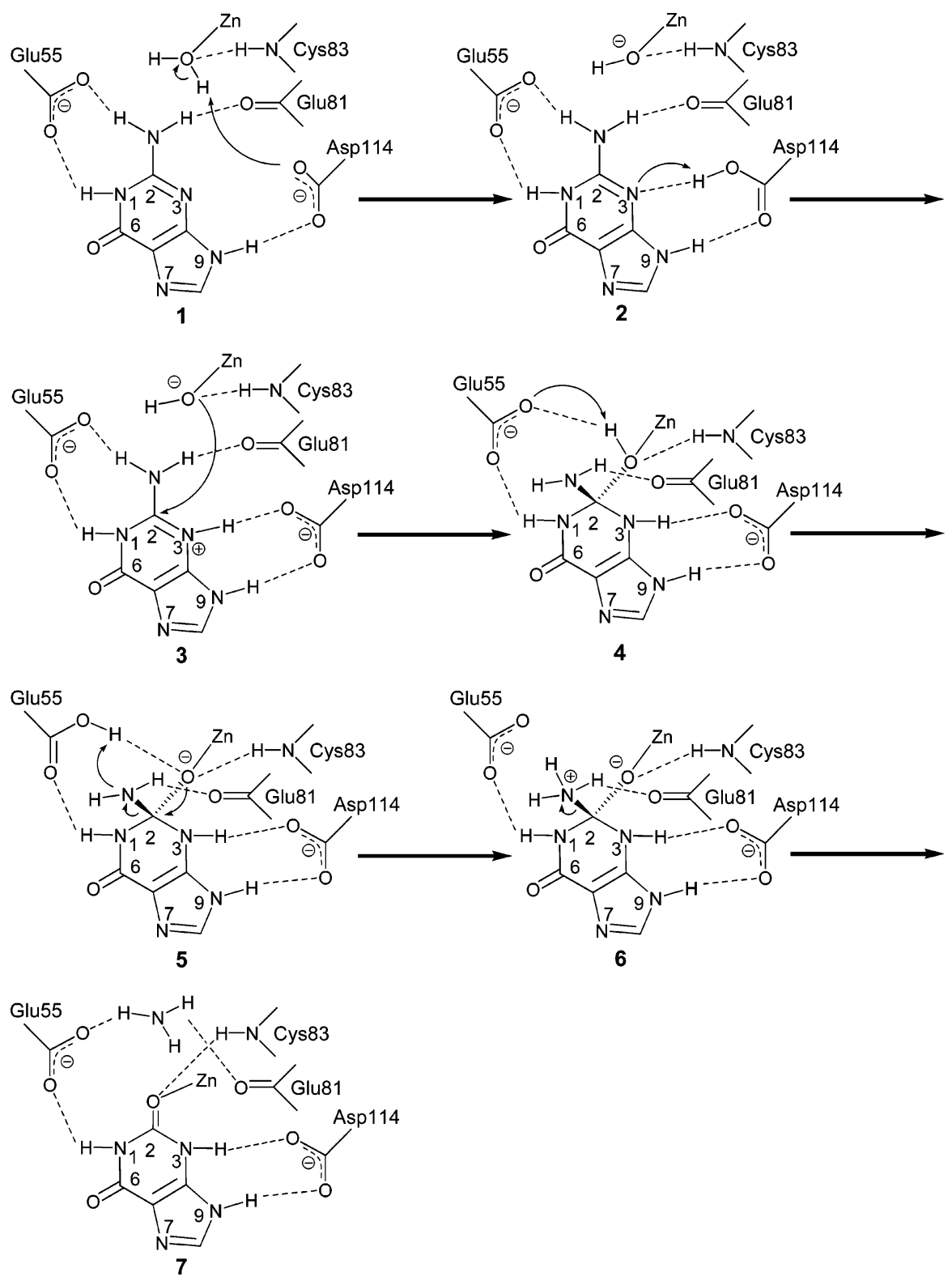

Figure 4. Reaction mechanism proposed for the deamination of guanine catalyzed by bGD. All the species were labeled with numbers (see text). The energy changes along the reaction path were calculated with ONIOM and the barriers (in parenthesis) were estimated on the basis of distance scans.

with an energy $7.9 \mathrm{kcal} / \mathrm{mol}$ higher than that of complex $\mathbf{8}$. After breaking the $\mathrm{Zn}-\mathrm{O}$ bond, xanthine is free to leave, and then water comes in and coordinates with the $\mathrm{Zn}$ to complete the catalytic cycle.

Alternatively, water might gain access to the $\mathrm{Zn}$ and assist the bond breaking, which would make the cleavage of $\mathrm{Zn}-\mathrm{O}$ bond and the binding of water a concerted step. To identify whether this is the case and the possible water path for this process, an MD simulation of Zn-bound xanthine was performed with the $\mathrm{Zn}-\mathrm{O}$ distance restrained to $3.10 \AA$ in subunit 1 to mimic the transition state for the cleavage of the $\mathrm{Zn}-\mathrm{O}$ bond and to $3.80 \AA$ in subunit 2 to mimic complex 9 with the $\mathrm{Zn}-\mathrm{O}$ bond cleaved. During the 2-ns simulation, no water was observed to get within $3.5 \AA$ of the $\mathrm{Zn}$ in either active site. Though three water molecules are present in both active sites, none can get access to the $\mathrm{Zn}$, because the path to the $\mathrm{Zn}$ is blocked by xanthine (data not shown). Then, the distance between $\mathrm{Zn}$ and $\mathrm{O} 2$ of xanthine was gradually reduced to 2.0 $\AA$ in subunit 1 (to mimic complex 8) and gradually increased to $4.8 \AA$ in subunit 2. Again, no water was observed close to the $\mathrm{Zn}$ in either active site in a 1-ns simulation. All these simulations suggested that the binding of water to the $\mathrm{Zn}$ is more likely to occur after the release of xanthine or at least after the relocation of xanthine in the active site.

Protonation of Asp114. As described earlier, the first step in the proposed mechanism is proton transfer from the Zn-bound water to the carboxyl group of Asp114. This may occur either before or after guanine binds to the active site. To investigate this process, the crystal structure was optimized by ONIOM without the bound imidazole but with keeping all the crystal water molecules and residues within $6 \AA$ around the active site (Figure 1B). One water molecule bridges the Zn-bound water and carboxyl OD1 of Asp114 by forming one hydrogen bond with the former as an acceptor and another with the latter as a donor (Figures 1B and 6). The bridging water also forms a hydrogen bond with the carbonyl of Glu81. The heavy atom distances are $2.64,2.60$, and $3.23 \AA$ for these three hydrogen bonds, indicating that this bridging water should be quite stable. The Zn-bound water is also hydrogen-bonded to Glu55 (Figures $1 \mathrm{~B}$ and 7). 


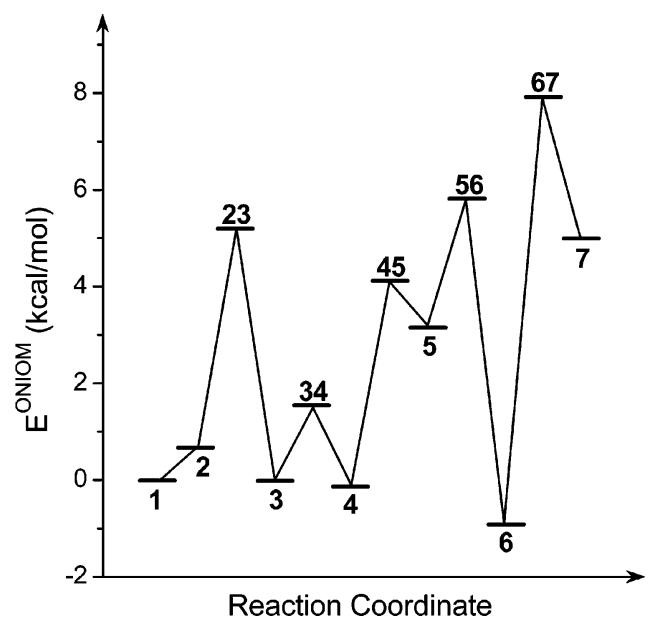

Figure 5. Schematic $E^{\mathrm{ONIOM}}$ energy profile for the mechanism depicted in Figure 4. The energy barriers $23,34,45,56$, and 67 corresponds to the transitions of the complexes $2 \rightarrow 3,3 \rightarrow 4,4 \rightarrow 5,5 \rightarrow 6$, and 6 $\rightarrow 7$, respectively. They are the upper bounds to the true reaction barriers as detailed in the text.
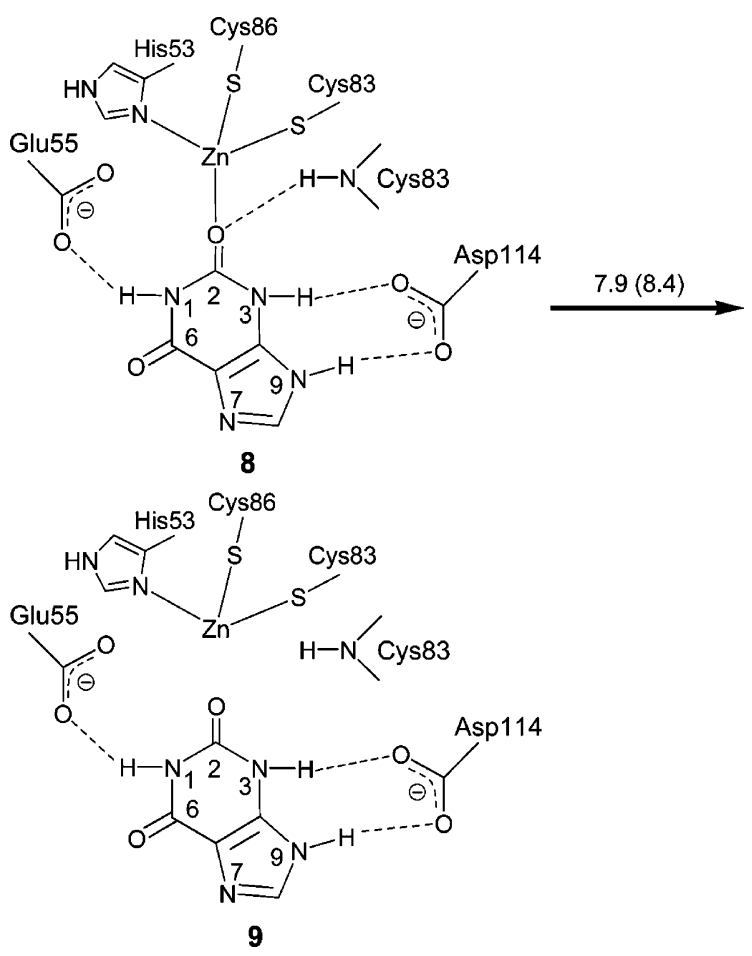

Figure 6. $\mathrm{Zn}-\mathrm{O}$ bond cleavage during the release of xanthine. Complex $\mathbf{8}$ is formed after the release of ammonia from complex $\mathbf{7}$. Energies are in $\mathrm{kcal} / \mathrm{mol}$.

The MD simulation of apo bGD also shows a bridging water molecule with similar interactions as observed in the ONIOM calculation and exhibits a dynamic character. During the first $150 \mathrm{ps}$ of the MD simulation, one (the first) water molecule bridges the Zn-bound water and OD1 of Asp114, the same as seen in the ONIOM calculation, but during the next $175 \mathrm{ps,}$ another (the second) water comes in and forms a two-water bridge. Then, in the next $680 \mathrm{ps}$, the one-water bridge resumes, and this second water molecule moves away to form a hydrogen bond with OD2 of Asp114. This one-water bridge is broken during the next $370 \mathrm{ps}$ and the first water moves close to and hydrogen bonds with the carboxyl group of Glu55. Thereafter, this second water moves back to OD1 and recovers the onewater bridge, and at the same time, a new water molecule
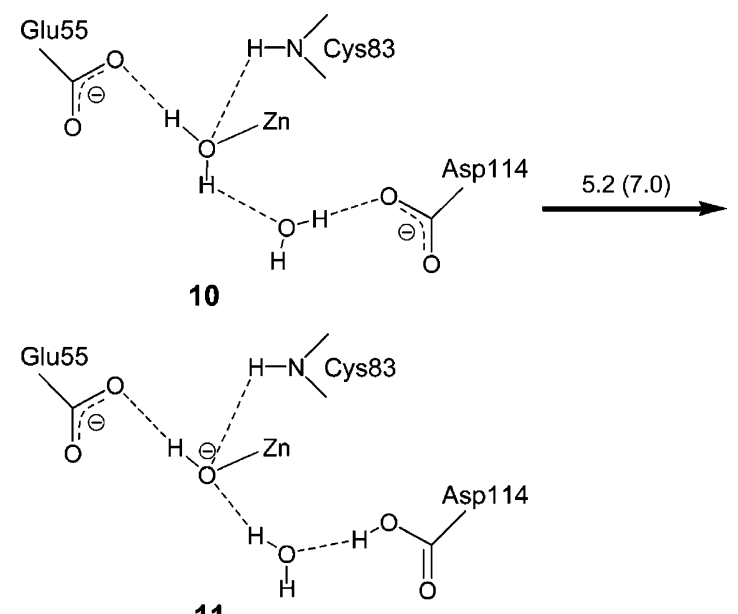

11

Figure 7. Proton transfer from the Zn-bound water to Asp114 through a water bridge. Energies are in $\mathrm{kcal} / \mathrm{mol}$.

migrates from solvent to the active site. Overall, a one-water (two-water) bridge exists during $70 \%(10 \%)$ of the $1.5-\mathrm{ns}$ simulation.

Since a similar water bridge was observed in both ONIOM and MD calculations, this water bridge should be stable and might assist the proton transfer from the $\mathrm{Zn}$-bound water to Asp114. The distance between the Asp114 carboxyl OD1 and the water proton which is involved in the hydrogen bond with OD1 was scanned in an ONIOM calculation; the maximum energy occurs at distance $1.20 \AA$ with the barrier $7.0 \mathrm{kcal} / \mathrm{mol}$ (Figure 7). In the end, the bridging water transfers its proton to OD1 and extracts one proton from the Zn-bound water. The energy barrier $7.0 \mathrm{kcal} / \mathrm{mol}$ should be considered an upper bound for the two-proton-transfer process, because only the distance between OD1 of Asp114 and the water proton involved in the hydrogen bond with OD1 was varied. The energy of the complex with protonated Asp114 and deprotonated Zn-bound water (11) is $5.20 \mathrm{kcal} / \mathrm{mol}$ higher than that of the complex with deprotonated Asp114 and Zn-bound water (10). Therefore, it is more likely that the proton stays with the $\mathrm{Zn}$-bound water instead of Asp114 in the apo enzyme. However, from the previous calculations, we know that after guanine binds, the energy difference between these two states is only $0.70 \mathrm{kcal} / \mathrm{mol}$ in favor of the $\mathrm{Zn}$-bound water. So, the binding of guanine shifts the equilibrium to the right side of Figure 7. It stabilizes the protonated Asp114 probably by formation of two hydrogen bonds between $\mathrm{N} 3$ and OD1 $-\mathrm{H}$ and between N9-H and OD2. However, the question comes up as to whether it is possible that the proton transfer from the Zn-bound water to Asp114 through the water bridge occurs after the binding of guanine.

To answer this question, we first tried to insert a water molecule between Asp114 and the Zn-bound water after guanine binds in the ONIOM calculation. After the energy minimization, the bridging water forms one hydrogen bond with the $\mathrm{Zn}$-bound water as an acceptor and another hydrogen bond with N3 instead of OD1 of Asp114. Different orientations of the inserted water were tried, but the same minimized structure was obtained. Thus, it is more likely that the proton transfers through the water directly to N3 instead of to Asp114 in this case. The proton of the Zn-bound water was transferred to the N3 of guanine by shortening the distance between $\mathrm{N} 3$ and the proton of the bridging water. At the distance $1.20 \AA$, one proton transfers from the $\mathrm{Zn}$-bound water to the bridging water. The barrier for this reaction is $14.7 \mathrm{kcal} / \mathrm{mol}$ and the end state is $8.2 \mathrm{kcal} / \mathrm{mol}$ higher than the starting state. This large barrier makes the proton 


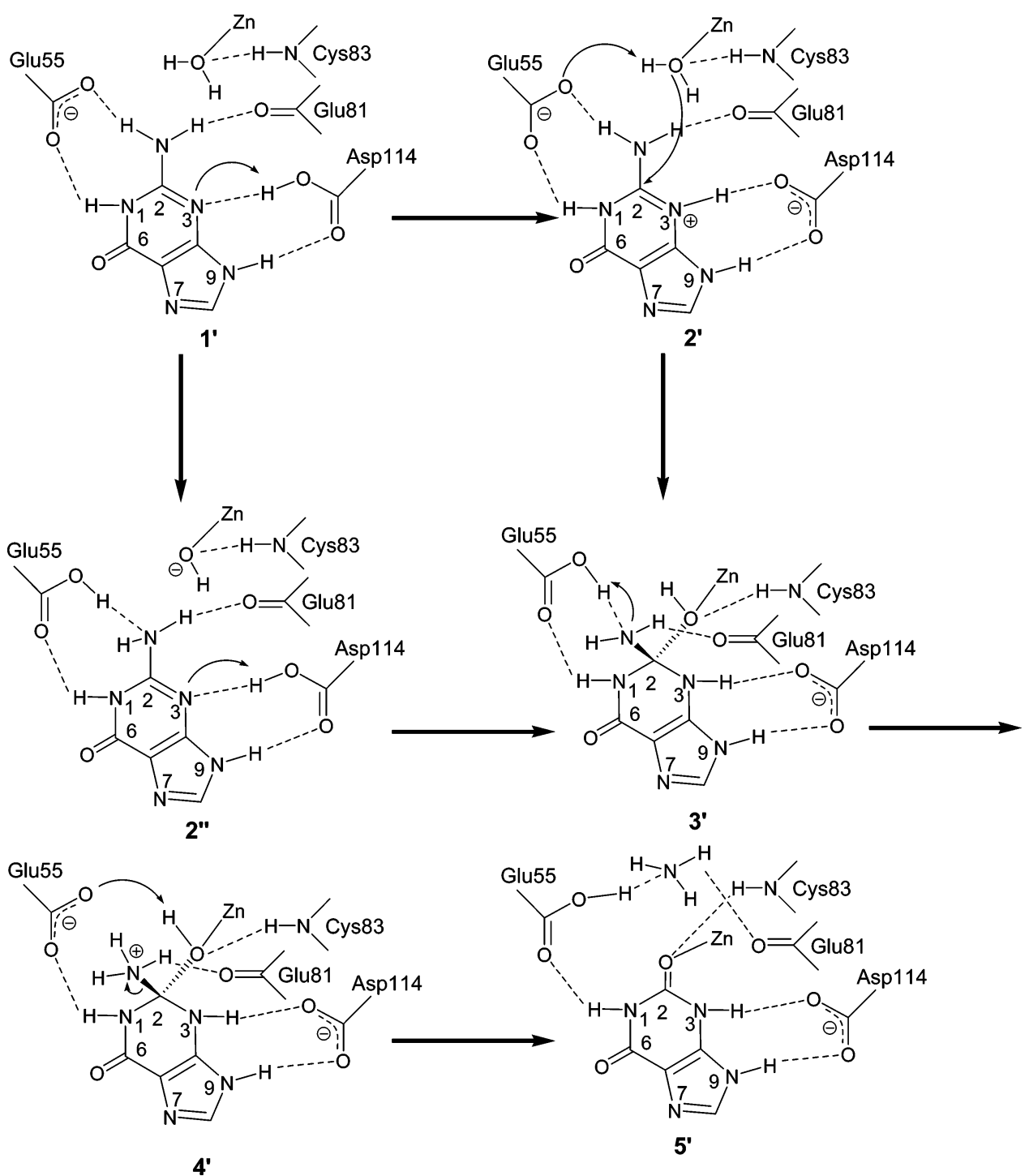

Figure 8. Proposed alternative mechanism with protonated Asp114.

transfer through the water bridge unlikely to happen compared with the previous proposed process. Furthermore, the inserted water molecule makes the region quite crowded such that the distance between $\mathrm{O}$ of the bridging water and the carbonyl $\mathrm{O}$ of Glu81 is only $2.31 \AA$, making the van der Waals interaction very unfavorable and the bridging water less stable.

Since the outer layer residues are fixed in an ONIOM calculation, which makes the space around guanine tight, the motion of these residues, especially Glu81, might be able to accommodate one water molecule in-between the $\mathrm{Zn}$-bound water and Asp114. However, the MD simulation shows that the water bridge does not exist when guanine binds to the active site. Though two water molecules are seen around the carboxyl group of Asp114, none of them forms hydrogen bonds with the $\mathrm{Zn}$-bound water because the presence of guanine makes the space too small for water molecules.

Therefore, all these results suggest that it is unlikely that the proton transfers to Asp114 (or to guanine) after guanine binds. Instead, it is more likely that proton transfer to Asp114 occurs through the water bridge right before the positioning of guanine in the binding pocket, as seen in ONIOM, which then pushes away the bridging water and stabilizes the protonated Asp114 by forming two hydrogen bonds with it. After this, the subsequent reactions occur as described above.
An Alternative Mechanism with Protonated Asp114. After investigating the catalytic mechanism and its variations with the Zn-bound water and deprotonated Asp114 as described above, we also explored the possibility of protonating the bound guanine with protonated Asp114, as depicted in Figure 8, where only the thermodynamic energies are evaluated, as summarized in Figure 9. First, Asp114 transfers its proton to guanine, which increases the energy by $\sim 9.6 \mathrm{kcal} / \mathrm{mol}$ (complex $\mathbf{1}^{\prime} \rightarrow$ complex $2^{\prime}$, Figures 8 and 9). Second, Glu55 extracts a proton from the $\mathrm{Zn}$-bound water and forms a hydrogen bond with the guanine amino group. At the same time, the Zn-bound hydroxide attacks C2 to form a tetrahedral intermediate, which increases the energy by $\sim 7.4 \mathrm{kcal} / \mathrm{mol}$ (complex $\mathbf{2}^{\prime} \rightarrow$ complex $\mathbf{3}^{\prime}$, Figures 8 and 9 ). Alternatively, first Glu55 extracts a proton from the Zn-bound water, which increases the energy by $\sim 13.6 \mathrm{kcal} / \mathrm{mol}$ (complex $\mathbf{1}^{\prime} \rightarrow$ complex 2", Figures 8 and 9); second, Asp114 transfers its proton to $\mathrm{N} 3$ and the $\mathrm{Zn}$-bound hydroxide attacks $\mathrm{C} 2$, which gives the same intermediate (complex $\mathbf{3}^{\prime}$, Figure 8) as above, which increases the energy by $3.4 \mathrm{kcal} / \mathrm{mol}$ (Figure 9). Third, Glu55 transfers its proton to the guanine amino group, and the energy goes up by another $1.2 \mathrm{kcal} / \mathrm{mol}$ (complex $4^{\prime}$, Figures 8 and 9). Fourth, Glu55 extracts the proton of the Zn-bound hydroxide and at the same time the $\mathrm{C} 2-\mathrm{N} 2$ bond breaks automatically, which drops the energy by $\sim 14.0 \mathrm{kcal} / \mathrm{mol}$ 


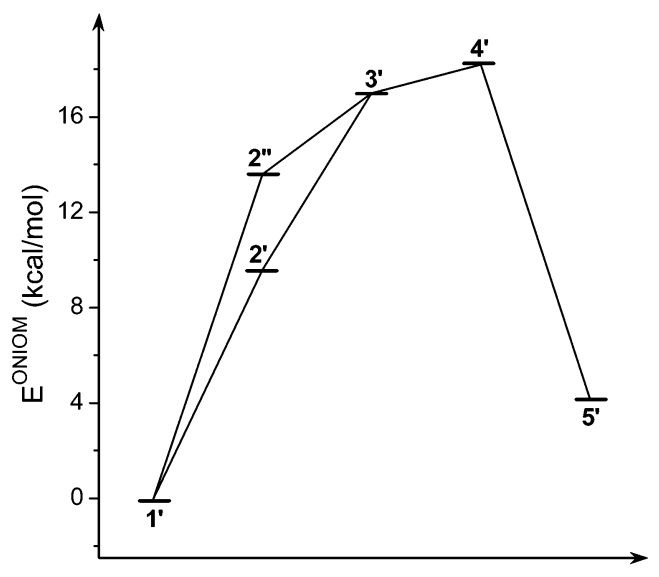

Reaction Coordinate

Figure 9. Schematic $E^{\mathrm{ONIOM}}$ energy profile for the alternative mechanism depicted in Figure 8. Only thermodynamic energies were calculated for this alternative mechanism.

(complex $\mathbf{5}^{\prime}$, Figures 8 and 9). Finally, we forced the proton to bind to ammonia by using a constraint. However, once this constraint is removed, the proton jumps back to Glu55, suggesting that this proton prefers to stay with Glu55. So, the final products are xanthine, ammonia, and protonated Glu55. The overall energy change for this mechanism is $\sim 4.2 \mathrm{kcal} /$ mol endothermic (Figure 9), which is comparable with the $\sim 5.0$ $\mathrm{kcal} / \mathrm{mol}$ from the previous mechanism (Figures 4 and 5). However, all the intermediates have much higher energies. The complex $\mathbf{4}^{\prime}$ is $18.2 \mathrm{kcal} / \mathrm{mol}$ less stable than complex $\mathbf{1}^{\prime}$ (Figures 8 and 9) compared with its analogue complex 6 that is $0.9 \mathrm{kcal} /$ mol more stable than complex $\mathbf{1}$ in the previous mechanism (Figures 4 and 5). This $18.2 \mathrm{kcal} / \mathrm{mol}$ difference would make this reaction far less efficient.

Dynamic Properties of bGD. Our MD simulations suggested that bGD is a relatively rigid protein. The all-atom massweighted root-mean-square fluctuation (RMSF) of the 26 residues in the active site (which were included in the ONIOM calculations) is quite small: only $0.45 \AA$ for complex $1,0.41$ $\AA$ for complex 8, and $0.44 \AA$ for complex 9. Thus, it is reasonable to fix the outer layer in these ONIOM calculations. The rigidity is also reflected by the high thermal stability of the enzyme and the rather low average B-factor values of the crystal structure ${ }^{11}\left(9.4,12.9,13.5,12\right.$, and $6.8 \AA^{2}$ for main chain atoms, side chain atoms, water molecules, imidazole atoms, and $\mathrm{Zn}$ atoms, respectively). Therefore, fixing the outer layer of the model system in the ONIOM calculations is a reasonable approximation. Furthermore, the hydrogen bond network of the guanine-bound enzyme complex (Figure 2 and complex $\mathbf{1}$ in Figure 4) was maintained in the MD simulation (Table 2). The hydrogen bond patterns between xanthine and the enzyme in complexes 8 and 9 (Figure 6) observed in the ONIOM calculations were also maintained in the MD simulations of the two complexes (Tables 3 and 4). Generally, the distances between heavy atoms in the MD were quite consistent with the quantum results, and most distances from ONIOM could be covered by the corresponding MD numbers within their fluctuation ranges (Tables $2-4$ ).

The outer layer of ONIOM has to be large enough to cover most of the environmental effect but has to be as small as possible to minimize the computational cost. To check whether 26 residues in ONIOM are sufficient, the interaction energies between guanine and its surroundings were calculated from snapshots of the 1.5-ns MD simulation. The average interaction energy is $-103.9 \pm 4.42 \mathrm{kcal} / \mathrm{mol}$ between guanine and those
TABLE 3: Hydrogen Bonds in Complex $8^{a}$

\begin{tabular}{|c|c|c|c|}
\hline & ONIOM & MD & \multirow[b]{2}{*}{ occurrence $(\%)$} \\
\hline & $\overline{\text { distance }(\AA)}$ & $\overline{\text { distance }(\AA)}$ & \\
\hline Asn42-NDH $\cdots O 6$ & 3.06 & $2.90(0.14)$ & 97.8 \\
\hline 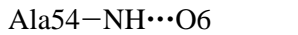 & 3.15 & $3.15(0.16)$ & 95.2 \\
\hline Glu55-OE1 $\cdots \mathrm{H}-\mathrm{N} 1$ & 2.73 & $2.79(0.12)$ & 83.2 \\
\hline Asp114-OD1 $\cdots \cdot \mathrm{H}-\mathrm{N} 3$ & 2.68 & $2.96(0.18)$ & 78.8 \\
\hline Asp114-OD2 $\cdots \mathrm{H}-\mathrm{N} 9$ & 2.69 & $2.78(0.10)$ & 100 \\
\hline Tyr156'-OH $\cdots$ N7 & 2.82 & $2.94(0.17)$ & 97.8 \\
\hline
\end{tabular}

${ }^{a}$ Hydrogen bonds are assigned when the distance between two heavy atoms $(\mathrm{O}$ or $\mathrm{N})$ is less than $3.5 \AA$ and the angle (heavy atomhydrogen-heavy atom) is greater than $120^{\circ}$.

TABLE 4: Hydrogen Bonds in Complex $9^{a}$

\begin{tabular}{|c|c|c|c|}
\hline & ONIOM & MD & \multirow[b]{2}{*}{ occurrence $(\%)$} \\
\hline & distance $(\AA)$ & $\overline{\text { distance }(\AA)}$ & \\
\hline Asn42-NDH $\cdots \mathrm{O} 6$ & 3.20 & $2.92(0.14)$ & 99.7 \\
\hline Ala54-NH $\cdots$ O6 & 3.11 & $3.20(0.15)$ & 91.9 \\
\hline Glu55-OE1 $\cdots \mathrm{H}-\mathrm{N} 1$ & 2.77 & $2.79(0.09)$ & 100 \\
\hline Asp114-OD $1 \cdots \mathrm{H}-\mathrm{N} 3$ & 2.64 & $2.79(0.09)$ & 100 \\
\hline Asp114-OD2 $\cdots H-\mathrm{H} 9$ & 2.73 & $2.81(0.11)$ & 100 \\
\hline 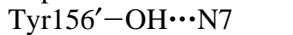 & 2.99 & $2.89(0.16)$ & 99.2 \\
\hline
\end{tabular}

${ }^{a}$ Hydrogen bonds are assigned when the distance between two heavy atoms $(\mathrm{O}$ or $\mathrm{N})$ is less than $3.5 \AA$ and the angle (heavy atomhydrogen-heavy atom) is greater than $120^{\circ}$.

26 residues compared with $3.54 \pm 3.62 \mathrm{kcal} / \mathrm{mol}$ between guanine and the rest of the system (including the solvent). Thus, it is sufficient to include those 26 residues in the ONIOM calculations.

\section{Discussion and Conclusion}

A catalytic mechanism reminiscent of that of $\mathrm{yCD}$ has been proposed for bGD. ${ }^{11}$ In that mechanism, the bound guanine is a tautomer with a proton attached to N3 (b in Figure 3 ) instead of to N1 (a in Figure 3). While this tautomer is not detectable in aqueous solution, ${ }^{14,15}$ it is possible that the enzyme may stabilize the rare tautomer over the most abundant one. Thus, we first investigated the tautomeric state of the bound guanine with ONIOM. The result showed that tautomer $\mathbf{a}$ is more stable than tautomer $\mathbf{b}$ in the active site of the enzyme. The energy difference $(5.8 \mathrm{kcal} / \mathrm{mol})$ is similar to that $(5.2 \mathrm{kcal} / \mathrm{mol})$ found for free guanine in aqueous solution, ${ }^{49}$ suggesting that the bound guanine is tautomer a just as free guanine in aqueous solution, and the enzyme does not alter the tautomeric state of guanine. This result is consistent with the interactions between the bound guanine and the active-site residues (Figures 2 and 3). The hydrogen bond patterns of the two tautomers are the same except those at positions 1 and 3 that undergo the tautomerization. In tautomer a, NH at position 1 forms a hydrogen bond with Glu55, whereas in tautomer $\mathbf{b}, \mathrm{NH}$ at position 3 forms a hydrogen bond with Asp114. Thus, there is no net hydrogen bond gain or loss during the tautomerization. The tautomeric state of the bound guanine is determined by the intrinsic chemical property of guanine rather than by the active-site residues of the enzyme.

The "new" tautomeric guanine demands a new catalytic mechanism, because Glu55 can no longer serve as a proton shuttle for the proton transfer from the Zn-bound water to guanine for the formation of the tetrahedral reaction intermediate (complex 4 in Figure 4). The combination of the ONIOM and MD studies that we carried out leads to a new mechanism for the bGD-catalyzed guanine deamination reaction as depicted in Figure 4. The first step in this mechanism is the transfer of a proton from the $\mathrm{Zn}$-bound water to Asp114. This process may 
be quite complex and rather dynamic in nature. In the apo form, proton transfer is possible through a bridging water but is not favorable (the energy increases by $5.2 \mathrm{kcal} / \mathrm{mol}$ ). In the guaninebound form, it is much less unfavorable (the energy only increases by $0.7 \mathrm{kcal} / \mathrm{mol}$ ) but difficult because no water bridge was found to be present. Water entry in the location that was observed in the ONIOM and MD might happen just before the positioning of guanine. The positioning of guanine breaks the water bridge and stabilizes protonated Asp114 by forming two hydrogen bonds with it (complex 2 in Figure 4). Second, Asp114 transfers its proton to N3. The first two steps shorten the distance between $\mathrm{C} 2$ and the Zn-bound hydroxide and favor the nucleophilic reaction. Third, Zn-bound hydroxide attacks C2 to form a tetrahedral intermediate with a rather low barrier, which also moves the Zn-bound hydroxide closer to OE2 of Glu55. Fourth, Glu55 transfers a proton from the Zn-bound hydroxide to the amino group by rotating its dihedral $\mathrm{CB}-\mathrm{CG}-$ $\mathrm{OE} 1-\mathrm{H}$ by $\sim 30^{\circ}$. At this point, the $\mathrm{C} 2-\mathrm{N} 2$ bond (complex 6 in Figure 4) has lengthened by $0.2 \AA$ compared to guanine, and that makes the $\mathrm{C} 2-\mathrm{N} 2$ bond cleavage more facile. Fifth, the $\mathrm{C} 2-\mathrm{N} 2$ bond is broken and ammonia forms, which gives the highest barrier $\sim 8.8 \mathrm{kcal} / \mathrm{mol}$ so far. Sixth, ammonia leaves the active site and xanthine is freed by the cleavage of the $\mathrm{Zn}-\mathrm{O} 2$ bond with a barrier $\sim 8.4 \mathrm{kcal} / \mathrm{mol}$ (Figure 6). Therefore, along the reaction path the highest barrier comes from the $\mathrm{C} 2-\mathrm{N} 2$ bond cleavage (Figure 5), while the barrier from the cleavage of the $\mathrm{Zn}-\mathrm{O} 2$ bond is slightly smaller. Then, xanthine leaves the active site and water moves in and binds to the $\mathrm{Zn}$ to complete the catalytic cycle. The deamination reaction is endothermic and is driven by the dissociation of products ammonia and xanthine.

This reaction path is different from those proposed for $\mathrm{yCD}^{21}$ and cytidine deaminases ${ }^{50,51}$ in an important respect. In the latter, only one residue, Glu64 in $\mathrm{yCD}^{12,13}$ and Glu104 in E. coli cytidine deaminase, ${ }^{52}$ which is structurally equivalent to Glu55 in $\mathrm{bGD}$, serves as the proton shuttle throughout the reaction paths. In bGD, in contrast, two residues, Glu55 and Asp114, are involved in the general acid and base catalysis. Asp114 plays an important role in the transfer of a proton from the $\mathrm{Zn}$-bound water to $\mathrm{N} 3$ of guanine to facilitate the formation of the reaction intermediate (complexes $\mathbf{1} \rightarrow \mathbf{4}$ in Figure 4), whereas Glu55 plays an important role in the proton transfer from the Zn-hydroxide to the amino group of the reaction intermediate to facilitate the cleavage of the amino group (complexes $\mathbf{4} \rightarrow \mathbf{7}$ in Figure 4). Thus, two proton shuttles are needed for the deamination of guanine by bGD.

An alternative mechanism with the proton for the protonation of guanine from protonated Asp114 rather than from the Znbound water (Figure 8) was also investigated. Even though the overall reaction energy difference between the product and reactant complexes is comparable to that with initially deprotonated Asp114, the energies of various intermediates along this reaction path are much higher. Furthermore, on the basis of the high-resolution crystal structure, there is no obvious structural feature that may elevate the $\mathrm{p} K_{\mathrm{a}}$ of Asp114. Therefore, this alternative mechanism (Figure 8) is less likely to occur than the mechanism based on deprotonated Asp114 (Figure 4). The $\mathrm{p} K_{\mathrm{a}}$ values of Asp and Glu residues can be determined after the sequential resonance assignment of bGD has been achieved by multidimensional NMR spectroscopy.

Twenty-six residues of the enzyme around the active site were included in the ONIOM calculation. Because only part of the protein is included, energy minimization of the outer layer without constraints might lead to an unrealistic expansion of the protein. Therefore, the outer layer was fixed in the ONIOM calculations, which will influence somewhat the energetics along the reaction coordinate. In this regard, it is reassuring that our MD simulations of the protein with explicit water molecules do lead to the same hydrogen bond network in the active site as in the ONIOM calculations, for both the reactant and product complexes, with consistent distances between heavy atom pairs. Therefore, the interaction between the ligand and its surroundings is well-defined and quite stable. The constraint on the outer layer residues did not introduce artifacts in the hydrogen bond analysis of the active site. Other evidence for the validity of this approach for bGD is found by examining the flexibility of active site in the MD simulations. The all-atom RMSFs of those 26 residues are only $\sim 0.4 \AA$ in both reactant and product complexes. The rigidity of the active site can explain why MD produces similar active-site interactions compared with the ONIOM results and also suggests that it is a reasonable approximation to freeze the outer layer in these ONIOM calculations.

The calculations we carried out can only provide a suggested reaction mechanism that needs to be verified by experiment, since several compromises between computational cost and accuracy must be made. As usual in ONIOM, the enzyme is truncated to include only important regions such as the active site, 26 residues within $6 \AA$ of the bound substrate guanine in this study, which necessitates freezing of the outer layer. In our calculations, reaction coordinates were chosen on the basis of the chemical and biochemical evidence, and the energetics were evaluated by scanning the relevant distances. As noted in the Methods section, this provides upper bounds to the transitionstate energies. While the MD provided different configurations of the enzyme for the ONIOM method, our calculations do not incorporate the effect of averages over different configurations and, therefore, cannot provide free energies of the various reaction steps. Studies using QM/MM methods have been performed on some aspects of the catalytic mechanisms of the related enzymes cytosine deaminase ${ }^{34}$ and cytidine deaminase. ${ }^{35,36}$ More definitive results on the catalytic mechanism of bGD may be obtained using these QM/MM approaches.

In conclusion, a new catalytic mechanism has been proposed for bGD on the basis of both ONIOM quantum chemical calculations and MD simulations. The mechanism is different from the previously proposed one in that the bound guanine in the new mechanism is in the most abundant tautomeric form as seen in aqueous solution and two residues, Glu55 and Asp114, act as proton shuttles in catalysis. The reaction is initiated by the protonation of N3 of the guanine via Asp114. The catalytic mechanism of bGD is unique in comparison with those of $\mathrm{yCD}^{21}$ and cytidine deaminases ${ }^{50,51}$ in that the former requires two proton shuttles and the latter requires only one proton shuttle.

Acknowledgment. This work was supported by the Quantitative Biology Modeling Initiative of Michigan State University, the Michigan Center for Biological Information of the Michigan Life Sciences Corridor, and NIH grants (GM58221 to H.Y. and GM47274 to R.I.C.).

\section{References and Notes}

(1) Nygaard, P.; Bested, S. M.; Andersen, K. A. K.; Saxild, H. H. Microbiology 2000, 146, 3061.

(2) Saint-Marc, C.; Daignan-Fornier, B. Yeast 2004, 21, 1359.

(3) Maynes, J. T.; Yuan, R. G.; Snyder, F. F. J. Bacteriol. 2000, 182, 4658.

(4) Paletzki, R. F. Neuroscience 2002, 109, 15. 
(5) Yuan, G.; Bin, J. C.; McKay, D. J.; Snyder, F. F. J. Biol. Chem. 1999, 274, 8175 .

(6) Giese, R. D.; Snyder, F. F. Genome 2002, 45, 276.

(7) Canbolat, O.; Durak, I.; Cetin, R.; Kavutcu, M.; Demirci, S.; Ozturk, S. Breast Cancer Res. Treat. 1996, 37, 189.

(8) Durak, I.; Beduk, Y.; Kavutcu, M.; Suzer, O.; Yaman, O.; Ozturk, H. S.; Canbolat, O.; Ulutepe, S. Cancer Invest. 1997, 15, 212.

(9) Kuzmits, R.; Seyfried, H.; Wolf, A.; Muller, M. M. Enzyme 1980 25,148 .

(10) Shiota, G.; Fukada, J.; Ito, T.; Tsukizawa, M.; Yamada, M.; Sato, M. Jpn. J. Med. 1989, 28, 22.

(11) Liaw, S. H.; Chang, Y. J.; Lai, C. T.; Chang, H. C.; Chang, G. G. J. Biol. Chem. 2004, 279, 35479.

(12) Ko, T.-P.; Lin, J.-J.; Hu, C.-Y.; Hsu, Y.-H.; Wang, A. H.-J.; Liaw, S.-H. J. Biol. Chem. 2003, 278, 19111 961.

(14) Miles, H. T.; Frazier, J.; Howard, F. B. Science 1963, 142, 1458.

(15) Shapiro, R. Prog. Nucleic Acid Res. Mol. Biol. 1968, 8, 73.

(16) Humbel, S.; Sieber, S.; Morokuma, K. J. Chem. Phys. 1996, 105, 1959.

(17) Svensson, M.; Humbel, S.; Froese, R. D. J.; Matsubara, T.; Sieber, S.; Morokuma, K. J. Phys. Chem. 1996, 100, 19357.

(18) Dapprich, S.; Komaromi, I.; Byun, K. S.; Morokuma, K.; Frisch,

M. J. J. Mol. Struct.: THEOCHEM 1999, 462, 1.

(19) Vreven, T.; Morokuma, K. J. Comput. Chem. 2000, 21, 1419.

(20) Frisch, M. J.; Trucks, G. W.; Schlegel, H. B.; Scuseria, G. E.; Robb, M. A.; Cheeseman, J. R.; Montgomery, J. A., Jr.; Vreven, T.; Kudin, K. N.; Burant, J. C.; Millam, J. M.; Iyengar, S. S.; Tomasi, J.; Barone, V.; Mennucci, B.; Cossi, M.; Scalmani, G.; Rega, N.; Petersson, G. A.; Nakatsuji, H.; Hada, M.; Ehara, M.; Toyota, K.; Fukuda, R.; Hasegawa, J.; Ishida, M.; Nakajima, T.; Honda, Y.; Kitao, O.; Nakai, H.; Klene, M.; Li, X.; Knox, J. E.; Hratchian, H. P.; Cross, J. B.; Adamo, C.; Jaramillo, J.; Gomperts, R.; Stratmann, R. E.; Yazyev, O.; Austin, A. J.; Cammi, R.; Pomelli, C.; Ochterski, J. W.; Ayala, P. Y.; Morokuma, K.; Voth, G. A.; Salvador, P.; Dannenberg, J. J.; Zakrzewski, V. G.; Dapprich, S.; Daniels, A. D.; Strain, M. C.; Farkas, O.; Malick, D. K.; Rabuck, A. D.; Raghavachari, K.; Foresman, J. B.; Ortiz, J. V.; Cui, Q.; Baboul, A. G.; Clifford, S.; Cioslowski, J.; Stefanov, B. B.; Liu, G.; Liashenko, A.; Piskorz, P.; Komaromi, I.; Martin, R. L.; Fox, D. J.; Keith, T.; Al-Laham, M. A.; Peng, C. Y.; Nanayakkara, A.; Challacombe, M.; Gill, P. M. W.; Johnson, B.; Chen, W.; Wong, M. W.; Gonzalez, C.; Pople, J. A. Gaussian 03, Revision B.05; Gaussian, Inc.: Pittsburgh, PA, 2003.

(21) Sklenak, S.; Yao, L. S.; Cukier, R. I.; Yan, H. G. J. Am. Chem. Soc. 2004, 126, 14879. 33

(22) Pawlak, J.; Bahnson, B. J.; Anderson, V. E. Nukleonika 2002, 47,

(23) Pelmenschikov, V.; Siegbahn, P. E. M. Inorg. Chem. 2002, 41, 5659.

(24) Torrent, M.; Vreven, T.; Musaev, D. G.; Morokuma, K.; Farkas, O.; Schlegel, H. B. J. Am. Chem. Soc. 2002, 124, 192.
(25) Saen-Oon, S.; Kuno, M.; Hannongbua, S. Proteins 2005, 61, 859

(26) Prabhakar, R.; Musaev, D. G.; Khavrutskii, I. V.; Morokuma, K. J. Phys. Chem. B 2004, 108, 12643.

(27) Yao, L. S.; Sklenak, S.; Yan, H. G.; Cukier, R. I. J. Phys. Chem. $B$ 2005, 109, 7500.

(28) Cui, Q.; Karplus, M. Adv. Protein Chem. 2003, 66, 315.

(29) Friesner, R. A.; Guallar, V. Annu. Rev. Phys. Chem. 2005, 56, 389.

(30) Gao, J. L. Acc. Chem. Res. 1996, 29, 298

(31) Gao, J. L.; Ma, S. H.; Major, D. T.; Nam, K.; Pu, J. Z.; Truhlar, D.

G. Chem. Rev. 2006, 106, 3188 .

(32) Gao, J. L.; Truhlar, D. G. Annu. Rev. Phys. Chem. 2002, 53, 467.

(33) Garcia-Viloca, M.; Gao, J.; Karplus, M.; Truhlar, D. G. Science 2004, 303, 186.

(34) Yao, L. S.; Yan, H. G.; Cukier, R. I. J. Phys. Chem. B 2006, 110, 26320

(35) Guo, H. B.; Rao, N.; Xu, Q.; Guo, H. J. Am. Chem. Soc. 2005, 127,3191

(36) Xu, Q.; Guo, H. J. Phys. Chem. B 2004, 108, 2477.

(37) Becke, A. D. J. Chem. Phys. 1993, 98, 5648.

(38) Lee, C. T.; Yang, W. T.; Parr, R. G. Phys. Rev. B 1988, 37, 785.

(39) Dewar, M. J. S.; Zoebisch, E. G.; Healy, E. F.; Stewart, J. J. P. J. Am. Chem. Soc. 1985, 107, 3902.

(40) Dudev, T.; Lim, C. J. Phys. Chem. B 2001, 105, 10709.

(41) Dudev, T.; Lim, C. J. Am. Chem. Soc. 2002, 124, 6759.

(42) Kuno, M.; Hannongbua, S.; Morokuma, K. Chem. Phys. Lett. 2003, 380,456

(43) Pearlman, D. A.; Case, D. A.; Caldwell, J. W.; Ross, W. S.; Cheatham, T. E.; Debolt, S.; Ferguson, D.; Seibel, G.; Kollman, P. Comput. Phys. Commun. 1995, 91, 1.

(44) Mahoney, M. W.; Jorgensen, W. L. J. Chem. Phys. 2000, 112, 8910

(45) Cornell, W. D.; Cieplak, P.; Bayly, C. I.; Gould, I. R.; Merz, K M.; Ferguson, D. M.; Spellmeyer, D. C.; Fox, T.; Caldwell, J. W.; Kollman, P. A. J. Am. Chem. Soc. 1996, 118, 2309.

(46) Ryckaert, J. P.; Ciccotti, G.; Berendsen, H. J. C. J. Comput. Phys. 1977, 23, 327.

(47) Essmann, U.; Perera, L.; Berkowitz, M. L.; Darden, T.; Lee, H.; Pedersen, L. G. J. Chem. Phys. 1995, 103, 8577.

(48) Berendsen, H. J. C.; Postma, J. P. M.; Vangunsteren, W. F.; Dinola, A.; Haak, J. R. J. Chem. Phys. 1984, 81, 3684.

(49) Jang, Y. H.; Goddard, W. A.; Noyes, K. T.; Sowers, L. C.; Hwang, S.; Chung, D. S. J. Phys. Chem. B 2003, 107, 344.

(50) Snider, M. J.; Reinhardt, L.; Wolfenden, R.; Cleland, W. W. Biochemistry 2002, 41, 415.

(51) Johansson, E.; Mejlhede, N.; Neuhard, J.; Larsen, S. Biochemistry 2002, 41, 2563.

(52) Betts, L.; Xiang, S.; Short, S. A.; Wolfenden, R.; Carter, C. W., Jr. J. Mol. Biol. 1994, 235, 635 .

(53) Kraulis, P. J. J. Appl. Crystallogr. 1991, 24, 946.

(54) Bacon, D. J.; Anderson, W. F. J. Mol. Graphics 1988, 6, 219.

(55) Merritt, E. A.; Bacon, D. J. Methods Enzymol. 1997, 277, 505. 